Relato de CAso

CASE REPORT

\title{
Alcaptonúria (Ocronose): Relato de Dois Casos
}

\section{Alkaptonuria (Ochronosis): Report of Two Cases}

\author{
Letícia R. Brandão(1), Brunela P. Borjaille ${ }^{(1)}$, Tatiana M. Hasegawa ${ }^{(2)}$, Renata F. Rosa ${ }^{(3)}$, \\ Elaine Azevedo ${ }^{(4)}$, Wiliam H. Chahade ${ }^{(5)}$
}

\section{RESUMO}

A alcaptonúria (ocronose) é um erro inato do metabolismo da fenilalanina e tirosina, transmitido de forma autossômica recessiva. Resulta da deficiência completa da enzima ácido homogentísico oxidase (HGO), causada por mutação no gene $3 \mathrm{q}(3 \mathrm{q} 2 \mathrm{l}-\mathrm{q} 23)$, levando ao acúmulo do ácido em diversos órgãos e tecidos, com aumento de sua excreção urinária. Os achados clínicos característicos incluem artropatia ocronótica, pigmentação anormal da cartilagem de outros tecidos conjuntivos e urina enegrecida. A incidência é rara, estimada em 1-4: 1.000.000 indivíduos, tendo maior prevalência em populações com alto grau de consangüinidade. A seguir, relataremos o caso de dois irmãos (um homem e uma mulher) com ocronose, discutindo sua patogênese, manifestações clínicas, diagnóstico e tratamento ${ }^{(1,2)}$.

Palavras-chave: ocronose, alcaptonúria, artropatia ocronótica.

\section{INTRODUÇÃO}

A alcaptonúria é uma doença hereditária autossômica recessiva, caracterizada pela deposição do ácido homogentísico em vários órgãos e tecidos ${ }^{(1)}$.

O termo ocronose introduzido por Virchow referese à coloração ocre observada à microscopia dos tecidos acometidos. Os pacientes excretam na urina grandes quantidades de ácido homogentísico, o qual pode ser espontaneamente oxidado em pigmento enegrecido. Esta reação pode ser acelerada pela adição de solução alcalina, dando origem ao termo alcaptonúria por Boedecker em $1866^{(1,3)}$.

As primeiras manifestações da doença ocorrem na infância como urina e cerume enegrecidos, porém os pacientes tornam-se sintomáticos somente em torno da quarta década de vida ${ }^{(1,4)}$.

\begin{abstract}
Alkaptonuria (ochronosis) is an autossomal recessive disorder which results from an innate error of phenylalanine and tyrosine's metabolism. This defect causes accumulation of homogentisic acid on the tissue and usually is excreted in the urine. This disorder results from a complete deficiency of the homogentisate 1,2 - dioxygenase (HGO) caused by chromosome 3q(3q21-q23) mutation. The clinical features include: ochronotic artropathy, black-gray pigmentation of the cartilage and the urine turns black. This is a rare disorder and incidence is about $1-4$ in 1.000 .000 of people and the prevalence is higher in consanguineous groups. The author will describe two affected brothers and discuss the pathophysiology, clinical features, diagnosis and treatment of ochronosis.
\end{abstract}

Keywords: ochronosis, alkaptonuria, ochronotic artropathy.

As complicações mais freqüentes são artropatia ocronótica, ocronose cardiovascular, cutânea e ocular, além de obstrução do trato genitourinário por cálculos ocronóticos. A artropatia ocronótica, manifestação mais incapacitante da doença, acomete, primariamente, grandes articulações e a coluna vertebral $^{(4,5)}$.

\section{DESCRIÇÃO DO CASO}

\section{CASO 1}

V.V., 61 anos, sexo masculino, branco, natural de São Paulo. O paciente procurou o Serviço de Reumatologia do Hospital do Servidor Público Estadual de São Paulo (HSPE), em 2001, com história de lombalgia mecânica, há 16 anos, com diminuição da mobilidade. Há sete anos, apresentou gonalgia bilateral de início insidioso, protocinética, com períodos de artrite e limitação funcional progressiva e artralgia

Serviço de Reumatologia do Hospital do Servidor Público Estadual de São Paulo "Francisco Morato de Oliveira” (HSPE-FMO). Recebido em 22/0 1/06. Aprovado, após revisão, em 16/07/06

1. Médica estagiária (E2) do Serviço de Reumatologia do HSPE-FMO

2. Médica residente (R2) em dedicação plena do Serviço de Reumatologia do HSPE-FMO

3. Médica assistente do Serviço de Reumatologia do HSPE-FMO

4. Médica encarregada do Ambulatório de Doenças Osteometabólicas do Serviço de Reumatologia do HSPE-FMO.

5. Diretor do Serviço de Reumatologia do HSPE-FMO.

Endereşo para Correspondência: Hospital Servidor Público Estadual (HSPE), Rua Pedro de Toledo, 1800, Vila Clementino, Caixa Postal 8570, São Paulo, SP, Brasil, telefone: (1 1 ) 5088-8099 
em ombros com limitação da mobilização. Relatava urina escura desde a infância. Ao exame físico: escleras de coloração azulada (Figura 1), pigmentação azulada em região palmar (Figura 2) e ouvido externo, cerume de coloração enegrecida; marcha antálgica; hiperextensão cervical com limitação a lateralização $\left(20^{\circ} \mathrm{D} / 20^{\circ} \mathrm{E}\right)$ e rotação $\left(40^{\circ} \mathrm{D} / 40^{\circ} \mathrm{E}\right)$; limitação a abdução em ombros $\left(50^{\circ} \mathrm{D} / 60^{\circ} \mathrm{E}\right)$; derrame articular em joelho esquerdo; teste de Schöber $<5 \mathrm{~cm}$. Biópsia de pele da região palmar direita: ocronose acentuada (Figura 3). Exames laboratoriais: sinoviograma com líquido inflamatório sem cristais. O hematológico e bioquímica sérica foram normais. Exames ultra-sonográficos: vias urinárias e próstata normais; joelho esquerdo com bursite subquadricipital e calcificações livres em seu interior, sinais de sinovite, tendinopatia crônica quadriciptal e patelar calcificada. Ecocardiograma com calcificações em valvas mitral e aórtica. Exames de raio X simples: a) coluna dorsolombar - calcificações e estreitamento dos discos intervertebrais, presença de sinal do vácuo e esclerose de platôs vertebrais (Figura 4); b) joelhos - diminuição do espaço articular e hipertrofia das espinhas tibiais (Figura 5); c) ombro direito - osteoartrite acromioclavicular e diminuição do espaço glenoumeral (Figura 6); d) sacroilíacas - esclerose bilateral e simétrica. Ressonância magnética de ombro esquerdo - osteoartrite acromioclavicular, glenoumeral e ruptura do manguito rotador (Figura 7). Sua urina, quando exposta ao sol, tornou-se enegrecida. A pesquisa do ácido homogentísico nesta foi positiva.

\section{CASO 2}

M.V., 52 anos, sexo feminino. Encaminhada para investigação, após realização de densitometria óssea, a qual sugeria calcificação de discos intervertebrais. Queixa de lombalgia de caráter mecânico de longa data e gonalgia progressiva bilateral. Apresentava quadro clínico e radiológico semelhante ao do irmão (descritos anteriormente).

A seguir, ilustraremos os casos relatados:

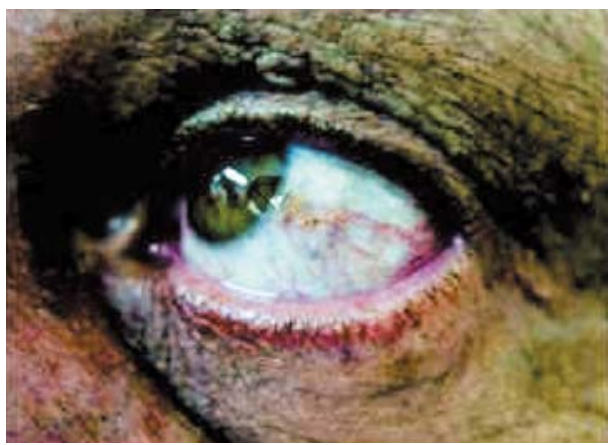

Figura 1 - Coloração azulada da esclera.

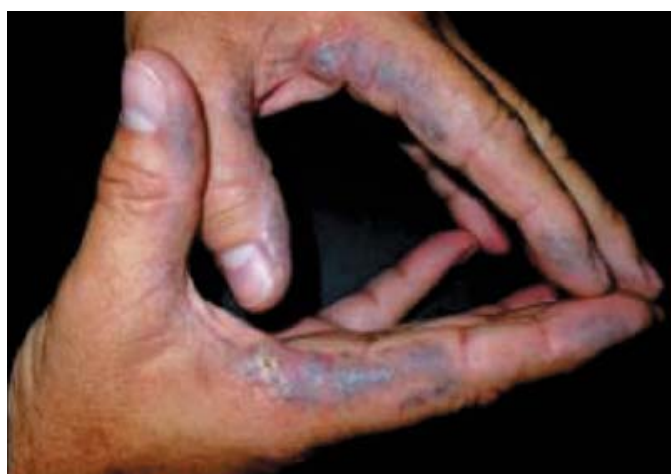

Figura 2 - Depósito de pigmentação ocronótica de coloração azulenegrecida na pele das mãos.

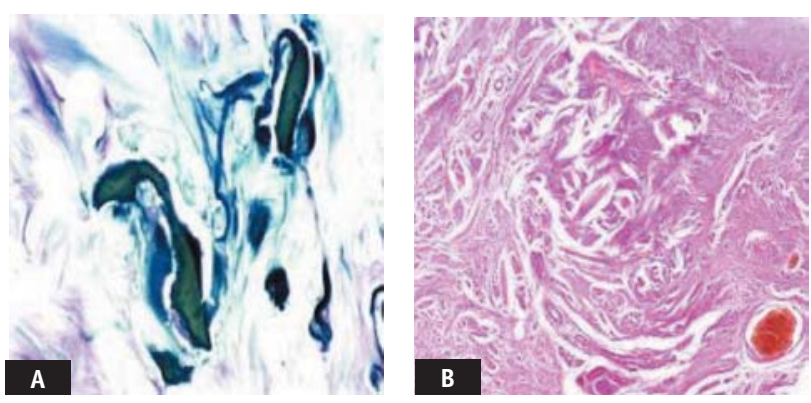

Figuras 3A e 3B - Biópsia de pele (região palmar direita): ocronose acentuada e hipererortoceratose e acantose (compativel com queratodermia marginal das palmas).

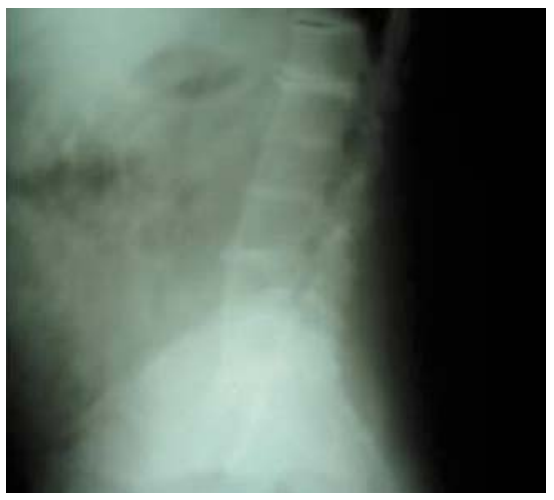

Figura 4 - Radiografia de coluna lombar em perfil.

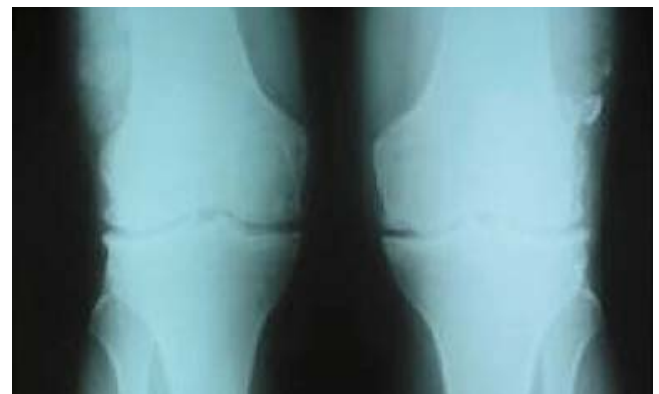

Figura 5 - Radiografia de joelhos em AP.

Rev Bras Reumatol, v. 46, n.5, p. 369-372, set/out, 2006 


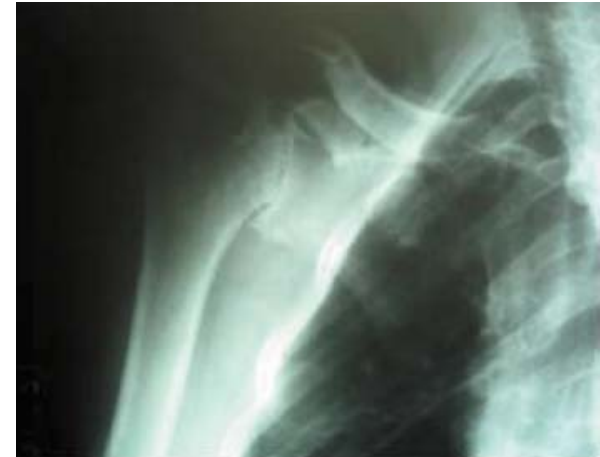

Figura 6 - Radiografia de ombro direito.

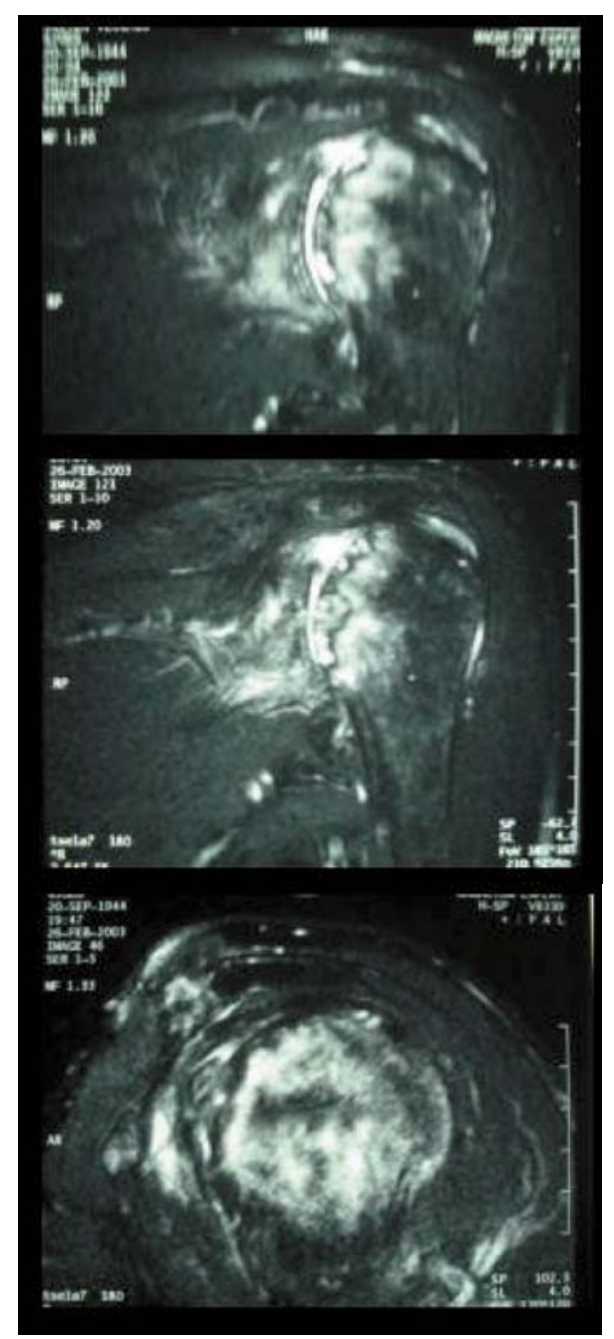

Figura 7 - Ressonância magnética de ombro esquerdo mostrando osteoartrite acromioclavicular e glenoumeral. Ruptura do manguito rotador e calcificação intrarticular.

\section{DISCUSSÃO}

O ácido homogentísico se fixa no colágeno, sendo, portanto, depositado nos tecidos conjuntivos, resultando em uma coloração azul escura na pele, orelhas, escleras e cartilagem $^{(1,6)}$.

O diagnóstico de alcaptonúria foi confirmado nos pacientes acima, baseado nos achados clínicos de comprometimento cutâneo, ocular, articular e cardiovascular, alterações radiográficas e pesquisa do ácido homogentísico na urina ${ }^{(1,7)}$.

A seguir, discorreremos sobre as principais manifestações clínicas da doença.

\section{ARTROPATIA OCRONÓTICA}

A patogênese da alcaptonúria envolve depósito de pigmento na cartilagem, cápsula articular, tendões e ligamentos. A cartilagem articular apresenta coloração marrom enegrecida mais evidente nas camadas profundas, devido a alta afinidade das fibrilas de colágeno pelo pigmento ocronótico. Erosões podem alcançar o osso subcondral em casos avançados. Joelhos, ombros e quadris são as articulações mais comumente acometidas. O envolvimento axial inclui hérnia discal, osteofitose e espondilose. Pacientes queixam-se de lombalgia, diminuição da mobilidade e da estatura $^{(1,4,8,9)}$.

\section{CUTÂNEAS}

A cartilagem do ouvido externo é tipicamente acometida, sendo freqüentemente o primeiro sítio cutâneo envolvido. A membrana timpânica e ossículos podem demonstrar alterações ocronóticas, caracterizando-se com hipoacusia ou surdez.

A pele exibe coloração azul enegrecida em regiões de alta densidade de glândulas sudoríparas e de tecido carti$\operatorname{laginoso}^{(1,8)}$.

\section{OCULAR}

O pigmento ocronótico deposita-se, primariamente, na esclera, conjuntiva, fissura interpalpebral, placa tarsal, córnea e pálpebras. A pigmentação da esclera está confinada a áreas expostas ao sol e, geralmente, precede o quadro articular. Geralmente, não ocorre alteração visual ${ }^{(1,10)}$.

\section{CARDIOVASCULARES}

Depósitos de pigmento ocronótico no sistema cardiovascular estão presentes no endocárdio, valvas cardíacas (aórtica e mitral) e na parede vascular. Sugere-se que estes 
sirvam de estímulo para calcificações distróficas, que eventualmente resultarão em estenose valvar ${ }^{(1,11)}$.

\section{SISTEMA RESPIRATÓRIO}

Presença de pigmento ocronótico na cartilagem hialina torna-se evidente na laringe, traquéia e cartilagem brônquica, sendo as repercussões clínicas raras como disfagia e rouquidão. A rigidez da cartilagem costal pode comprometer a função respiratóriai ${ }^{(1,6)}$.

\section{TRATO GENITOURINÁRIO}

O pigmento ocronótico pode formar cálculos na bexiga, rins, ureteres e uretra. O local mais acometido é a próstata, cujo $\mathrm{pH}$ alcalino resulta na rápida polimerização do ácido homogentísico. Os cálculos resultam tanto em obstrução vesical como prostática, ocorrendo infecções repetidas do trato urinário e uremia, respectivamente ${ }^{(1,4,6)}$.

\section{OUTROS SÍTIOS}

Outros locais menos freqüentes de depósito incluem os dentes, sistema nervoso central (SNC) e órgãos endó$\operatorname{crinos}^{(1,4)}$.

A diversidade de manifestações clínicas são suficientes para se chegar ao diagnóstico ${ }^{(1,6)}$.

A história familiar presente, dosagem do ácido homogentísico urinário e histopatologia ajudam a confirmar seu diagnóstico $^{(1)}$.

$\mathrm{Na}$ histopatologia, observamos o pigmento amareloacastanhado ou ocre na derme através da coloração de HE. Grânulos finos de pigmento localizam-se nos macrófagos

\section{REFERÊNCIAS}

1. Daniel K, Thomas B: Ochronosis. In Klippel's textbook of Rheumatology. Phyladelphia, Mosby 2: 28.1-28.4, 1998.

2. Janocha $S$, Wolz W, Srsen $S$, et al: The human gene for alkaptonuria (AKU) maps to chromosome 3q. Genomics 19: 5-8, 1994.

3. Phornphutkul C, Introne WJ, Perry MB, et al: Natural history of alkaptonuria. N Engl J 374: 2111-21, 2002.

4. Mulier M, Willems K: Ochronosis: Clinical manifestations. Belgian orthweb project, case of month, august 1997. httpllwww.orthoweb.be/cases/.

5. Lima ACR, Navarro ML, Provenza JR, Bonfiglioli Rl: artropatia Ocronótica: Relato de Caso. Rev Bras Reumatol 40: 213-6, 2000 .

6. Knubone TS, Selner AJ: Ochronosis and alkaptonuria. Case Report and Literature Review. J am Pediatr Med Assoc 85: 554-5, 1995. da derme. O pigmento também deposita-se nas células endoteliais, membrana basal e células secretoras das glândulas sudoríparas $^{(1,6)}$.

Ocorre deposição de pigmento no citoplasma dos condrócitos, resultando em degeneração das fibras de colágeno. Há fragmentação da cartilagem articular e fagocitose das fibrilas de colágeno pelos macrófagos sinoviais. Os fragmentos levam a um quadro de sinovite inespecífica ${ }^{(1,6)}$.

O diagnóstico diferencial deve incluir artropatia hemofílica, sinovite vilonodular pigmentada, artropatia associada a hemocromatose e espondilite anquilosante ${ }^{(1)}$.

Artropatia ocronótica não apresenta cura até o presente momento, pois a deficiência da enzima não pode ser tratada. Deve ser feita restrição de tirosina e fenilalanina da dieta, o que reduziria a excreção do ácido homogentísico na urina ${ }^{(1,}$ 12) . A artropatia é irreversível, embora a dieta possa prevenir a progressão da doença. Alguns estudos sugerem que altas doses do ácido ascórbico previnam a interação do pigmento ocronótico com os tecidos. Ensaios clínicos estão avaliando a eficácia do nitisinose (inibidor da enzima precursora do ácido homogentísico $)^{(1,12)}$. A terapêutica baseia-se em medidas sintomáticas como o uso de analgésicos, antiinflamatórios não-hormonais (AINHs), fisioterapia, infiltração intra-articular com corticóide. Finalmente, artroplastia de ombros, quadris e joelhos se faz necessária naqueles casos graves de artropatia ocronótica ${ }^{(1)}$. O paciente do caso 1 , com artropatia ocronótica, evoluiu para prótese de ombro esquerdo aos 59 anos de idade e está aguardando prótese em joelhos.

Declaramos a inexistência de conflitos de interesse.
7. Alparslan L, Weissman BN: Imagin. In: Harris Jr, RC Budd, GS Firestein et al(eds). In:Kelley's Text book of Rheumatology. Philadelphia, W.B. Saunders 1: 763-4, 2005.

8. Gutzmer R, Herbst RA, Kiehl P, Kapp A, Weiss J: Alkaptonuric ochronosis: report of two affected brothers. J Am Acad Dermatol 37: 305-7, 1997.

9. Cortina R, Moris C, Astudillo A, Gosálbez F, Cortina A: Familial ochronosis. Eur Heart J 16: 285-6, 1995.

10. Zannoni VG, Lomtevas N, Goldfinger S: Oxidation of homogentisic acid to ochronotic pigment in connective tissue. Biochim Biophys Acta 177: 94-105, 1969.

11. Kocyigit H, Gurgan A, Terzioglu R, Gurgan U: Clinical, radiographic and echocardiographic findings in a patient with ochronosis. Clin Rheumatol 17: 403-6, 1999.

12. Forslind K, Wollhein FA, Akesson B, Rydholm U: Alkaptonuria and ochronosis in three siblings: ascorbic acid treatment monitored by urinary HGA excretion. Clin Exp Rheumatol 6: 289-92, 1988. 